\title{
A comparative life cycle assessment (LCA) of alternative material for Australian building construction
}

\author{
Hangyong (Ray) Lu ${ }^{1, *}$, Ali El Hanandeh ${ }^{1}$, Benoit Gilbert ${ }^{2}$, and Henri Bailleres ${ }^{3}$ \\ ${ }^{1}$ School of Engineering, Griffith University, 170 Kessels Road, Nathan, QLD 4111, Australia. \\ ${ }^{2}$ School of Engineering, Griffith University, Parklands Drive Southport, Gold Coast, QLD, 4222, \\ Australia. \\ ${ }^{3}$ Salisbury Research Centre, Department of Agriculture, Fisheries and Forestry, Queensland \\ Government, Australia
}

\begin{abstract}
The use of wood is seen as a sustainable alternative to reduce environmental impacts in building and construction sector. The low quality hardwood logs from plantation thinning are enhanced by producing engineered wood such as laminated veneer lumber (LVL). Nevertheless, engineered wood requires the use of chemicals and energy that may reduce its environmental benefits. A life cycle assessment (LCA) was conducted to compare the environmental performance of LVL produced from forestry thinning and final harvest to steel and concrete. The functional unit used in this study was a 1-m-long structural beam in a continuous beam system of 6-m-span designed according to the Australian standards. The Global Warming Potential (GWP) and embedded energy were assessed. The results indicated that LVL beam from thinned logs presented the lowest GWP impact (5.22kg-CO2-Eq). However, due to significant energy requirements for wood drying, the embedded energy in LVL was $186.78 \mathrm{MJ}$ which is only marginally less than steel $(216.86 \mathrm{MJ})$ but significantly less than concrete (352.82MJ). LVL from mature hardwood logs had slightly higher GWP than that produced from thinning; mainly due to extra energy and materials consumption in the plantation stage. Furthermore, LVL produced from mature trees had higher embedded energy than steel.
\end{abstract}

\section{Introduction}

The building and construction sector currently contributes approximately a quarter of the total Greenhouse gas (GHG) emissions in Australia and it is expected to increase by $110 \%$ by 2050 [1]. That is mainly attributed to the consumption of highly energy intensive materials such as concrete and steel, which leads to significant environmental impacts [2]. Wood and wood-based products are promoted as sustainable and renewable construction materials [3]; and their use has been increasing steadily over the past few decades [4].

Wood is generally identified as the most sustainable structural material and strongly recommended for substituting high-energy intensive products $[4,5]$. Increasing use of wood-

\footnotetext{
* Corresponding author: hangyong.lu@griffithuni.edu.au
} 
based material could reduce the net GHG emissions because of the relatively low energy requirement during wood products manufacturing stage compared to conventional materials [6]. In addition, wood substitution in long-life-span wood products results in accumulated carbon storage [7]. However, the benefits of using wood products will only be realised if wood is sourced from sustainable sources using environmentally responsible practices.

Nowadays, up to $40 \%$ of Australian forests are lost due to excessive harvesting. In response to growing environmental concerns about the sustainability of native forestry practices, agreements have been signed to progressively phase out logging of native forests in Australia. Plantations are now being promoted as a long-term wood supply strategy in Australia [8]. Thinning processes is a common practice, which is carried out to ensure the quality of the final harvest. Up to $70 \%$ of trees are removed by the age of 13 to 15 years [9]. The thinned logs are usually not suitable for sawn timber applications because of the high rate of defects [9]. Engineered wood products can reduce the effect from the natural defects and convert it to more uniform structural products, with higher strength and less variability in mechanical properties compared to sawn timber [10]. Engineered wood products are commonly made by forming veneers, strands and flakes through peeling, chipping or slicing processes and bonded together with adhesives to form wood panels or other shaped structural products $[10,11]$. Engineered wood products have been increasingly accepted as a costcompetitive product building material [3]. Recently, engineered wood products produced from low value thinned logs were also used as substitute to replace energy-intensive materials $[3,12]$.

Structural Laminated Veneer Lumber (LVL) is produced by gluing layers of wood veneer sheets together with the grain of all plies running in the same direction. Compared to sawn timber, LVL has largely improved mechanical properties and used as an appropriate alternative in building structural purposes [11]. LVL can be manufactured in different sizes, such as floor beams, scaffold planking, as well as the flange material for prefabricated wood I-joists. However, many researchers mentioned that the engineered wood products may lead to much higher environmental impacts during manufacturing stage mainly due to chemicals consumption in the wood preparation phase $[13,14]$. While some researchers believed that engineered wood building design offered significantly lower environmental impacts; others reported that when considering cradle-to-grave processes, the energy requirements of engineered products are nearly identical to concrete $[15,16]$. Therefore, research is still needed to understand the environmental performance of engineered wood applications in building construction using comprehensive assessment.

Life cycle assessment (LCA) is a standardized method (ISO 14040:2006) which allows comprehensive assessment of products and services throughout all life stages [17]. However, LCA result can be affected by several factors such as, system boundaries, service life, manufacturing technology, energy sources, transportation distances, as well as waste management options. The existing studies could not represent the types of residential buildings commonly constructed in Australia, which makes it difficult to apply their findings to the Australian building sector. This study aims to obtain a quantitative measurement about the environmental impacts of using engineered wood in Australian residential building construction and compare it to the most commonly used material choices. The system boundaries start from hardwood plantation to the final waste disposal. Result of this study can be used to support residential building designers and builders, in making informed choices regarding the environmental impacts of construction material selection during building design and development. 


\section{Methods}

\subsection{Goal and scope}

The aim of this study was to conduct a comparative life cycle assessment of using engineered wood material (LVL) manufactured from hardwood plantation logs, steel and concrete for constructing residential building in Australia. This LCA was conducted using OpenLCA software [18], following the International Organisation for Standardisation (ISO14040:2006) [17]. All the input energy and materials and output products, emissions and wastes were calculated as described in the Life Cycle Inventory Analysis section. The life cycle inventory (LCI) data of products manufacturing and energy consumption were collected from relevant literature and LCI databases. Global warming potential (GWP) and embedded energy were the two impact indictors assessed in this study. ReCiPe Midpoint $(\mathrm{H})$ life cycle impact assessment (LCIA) method was used for the characterization of the emissions into the relevant impact categories.

\subsubsection{Functional unit}

The functional unit in this study was referenced as a $1 \mathrm{~m}$ long section of a structural beam in a continuous beam system with $6 \mathrm{~m}$ spans made from engineered wood, concrete and steel following the respective Australian residential multi-stories apartment building construction codes for each material. The service life was assumed as 60 years based on Australian average building life span [19]. The specific structural details of different beams are presented in Figure 1.

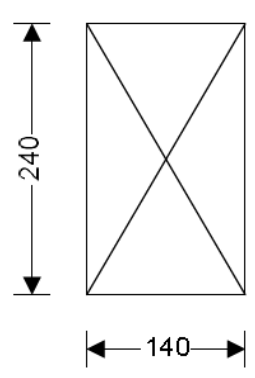

(a)

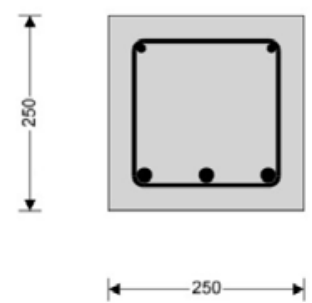

(b)

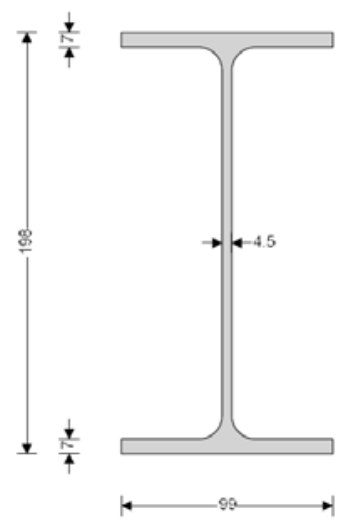

(c)

Fig. 1. (a) LVL Beam; (b) Concrete Beam Structure; (c) Steel Beam. All dimensions are in mm

\subsubsection{System boundaries}

The study provides a 'cradle-to-grave' LCA for laminate veneer lumber (LVL), concrete and steel beams for building construction based on resources from South-east Queensland. The system boundaries consider three life-cycle stages: raw material extraction, product manufacturing, and end-of-life treatment.

The engineered LVL beams manufactured using hardwood thinned logs from midrotation thinning and mature plantation hardwood from final harvest were designed as two 
scenarios. The system boundaries both start from hardwood plantation and up to second thinning and final harvesting, respectively. The hardwood logs are then transported to the mill for further manufacturing. The final products are transported to the building construction site using road truck. For the end-of-life treatment, the most environmentally feasible option was selected for each material. Incineration with energy recovery was the selected option for end-of-life management of LVL following the findings of Lu \& El Hanandeh [20]. On the other hand, steel was assumed to be $100 \%$ recycled and concrete was sent to landfill. Furthermore, the data used in this study were only used for representing Australian current state of art.

\subsection{Life Cycle Inventory ( $\mathrm{LCl}$ ) analysis}

The inventory analysis involves data collection and analysis for the life cycle of the building construction material. For each stage of the product life cycle, energy and raw materials consumption, products, waste, and emissions were all determined.

\subsubsection{LCl of $L V L$}

The LVL beam was designed based on Australian Standards on Timber Structure Design AS1720.1 (2010), Timber structures - Design methods [21]. The dimensions were presented in Figure 1-a. The LCI for the LVL beam starts with the plantation stage, which includes seedling production; site preparation, tree planting, and application of herbicides and fertiliser and harvesting. Electricity is used during greenhouse operations, while diesel fuel and lubricants are required to power equipment for a series of forestry practise. The outputs are the green thinned logs from mid-rotation thinning and mature hardwood logs from final harvest. The non-merchantable slash and branches are usually treated by mechanical activities on site and were excluded in this LCA.

The LCI was conducted based on the current state of the art of hardwood plantation operations in South-east Queensland, Australia. The data was collected from published LCI for Australian forestry and wood products [22]. As thinned logs are a co-product of the forestry operation, economic allocation as reported by May et al. [22] were used to split the impacts between thinned and mature logs in the ration of $1: 3$. The production of $1 \mathrm{~m}^{3}$ of hardwood from thinned logs requires $6.8 \mathrm{~L}$ of diesel, $73.10 \mathrm{kWh}$ of electricity, $0.12 \mathrm{~L}$ of lubricant, and $0.08 \mathrm{~kg}$ of steel. The quantity of fertiliser and herbicide consumption were also sourced.

During LVL beam manufacturing process, the hardwood logs are mechanically removed barks and cut to a certain length. The wood logs are then pre-conditioned using hot steam to ensure the logs are easier to peel and reduce veneer breakage [23]. The pre-conditioned logs are then peeled using a spindle-less veneer lathe with a high conversion rate around $70 \%$ [24]. The peeled veneers are moved to a clipper to be cut to appropriate widths. Veneer drying is an energy intensive process requiring approximately 3,800 MJ per cubic metre of hardwood veneer [25]. However, wood fuel constituted up to $80 \%$ of the total energy requirement with the remainder sourced from natural gas and electricity. The dried veneers are then glued and formed into LVL beam by Phenol-formaldehyde (PF) adhesive, which is commonly used for the engineered wood production [26]. After compressing, the LVL beam is sent to a finishing area for trimming and sanding. The air-dried density of hardwood LVL product is approximately $787 \mathrm{~kg} / \mathrm{m}^{3}$. Wood wastes generated during manufacturing such as veneers trim and sawdust are recycled as woody biomass fuel and combusted in boiler. LCI data of LVL manufacturing was collected based on our primary data and recently published relevant literatures [23, 25, 27], which represents common manufacturing practices in Australian mills. 
The main inputs to manufacture $1 \mathrm{FU}$ of structural LVL beam are: $0.056 \mathrm{~m}^{3}$ of hardwood logs; $5.04 \mathrm{~kg}$ of PF resin; and $0.147 \mathrm{~kg}$ of preservative. The energy consumed during LVL manufacturing is mainly sourced from wood waste combustion in biomass boiler (Approximately $169 \mathrm{MJ}$ ). The other energy used includes $11.73 \mathrm{kWh}$ of electricity, 0.11 litres of LPG, and 12MJ of natural gas. Transportation process required in the entire life cycle was approximately $11.22 \mathrm{tkm}$. In addition, 21.5 litres of water are consumed through the entire manufacturing process. The outputs comprised $1 \mathrm{FU}$ of LVL beam $\left(0.0336 \mathrm{~m}^{3}\right)$. Additionally, $12.7 \mathrm{~kg}$ of the wood waste generated during manufacturing is sent to boiler for energy production.

Engineered wood waste incineration for energy recovery was considered as the most appropriate scenarios for final disposal in Queensland region [20]. This LCA assumed that LVL beam was combusted in large cogeneration plant to generate electricity, which can be distributed to the local main grid. The bottom ash was assumed to be disposed in a landfill. The LCI data of engineered wood in incineration is adopted from Lu \& El Hanandeh [20]. The energy recovery through wood waste combustion was modelled as energy credit due to the avoidance of combustion of virgin feedstock according to the current Queensland electricity grid mix. It was estimated that $22 \mathrm{kWh}$ of electricity could be generated per functional unit.

\subsubsection{LCl of concrete structural beam}

The concrete beam (Figure 1-b) was designed based on The New Australian Standard for Concrete Structures - AS3600 (2009) [28]. The LCI data on concrete and steel were sourced from the US LCI [29]. The concrete beam manufacturing process required $67.33 \mathrm{kWh}$ of electricity, $4.15 \mathrm{~m}^{3}$ of natural gas, $0.51 \mathrm{~L}$ of diesel fuel and $0.22 \mathrm{~L}$ of gasoline. The material required for $1 \mathrm{FU}$ of concrete beam included $9.86 \mathrm{~kg}$ of steel, $25.64 \mathrm{~L}$ of water, $35.48 \mathrm{~kg}$ of cement as well as $102.93 \mathrm{~kg}$ of aggregate [30]. The transportation is assumed to be using Bdouble truck. The total transportation distance was estimated as $250 \mathrm{~km}$ (i.e. $150 \mathrm{~km}$ during material extraction, $50 \mathrm{~km}$ during beam transports to building construction site, and $50 \mathrm{~km}$ during final disposal). Concrete is demonstrated as an inert waste that is unlikely to be recycled [31]. Hence, the used concrete was assumed to be treated in landfill, meanwhile $85 \%$ of the reinforcing steel was recycled [32]. The environmental impacts of construction and closure of landfill facilities was assumed to be proportional to the mass of disposed waste beams.

\subsubsection{LCl of steel structural beam}

In accordance with Australian Standard for Steel Structures - AS4100 (1998) [33], steel beams are typically manufactured from hot rolled sheet steel. The dimensions of steel beam are shown in figure 1-c. The LCI data of steel beam manufacturing was sourced from published LCI data on steel production $[30,34]$. The energy required for manufacturing $1 \mathrm{FU}$ of steel beam included $56.73 \mathrm{kWh}$ of electricity, $3.62 \mathrm{~m}^{3}$ of natural gas, $0.13 \mathrm{~L}$ of diesel and $0.32 \mathrm{~L}$ of gasoline. The total steel required was calculated as approximately $18.33 \mathrm{~kg}$. The transportation processes considered in this study included transporting raw material to manufacturing facilities $(150 \mathrm{~km})$, transporting steel beam to the building construction site $(50 \mathrm{~km})$ as well as transporting used beams to recycle sites $(50 \mathrm{~km})$. In final disposal stage, steel beams were assumed to be $100 \%$ recycled reported [35]. The LCI data for scrap steel recycling was sourced from published literature $[30,36]$. 


\section{Results and discussions}

To assess the overall GWP of the different beams, impact indicator values were added throughout the whole stages from material extraction to final disposal. The GHG emissions and energy consumption in each stage of the assessed options are presented in Figure 2 (a, b). Raw material extraction stage contributed significant GWP in both concrete and steel options. However, the LVL options indicated that manufacturing stage contributed the most significant impact in GWP mainly due to the PF resin consumption. In case of embodied energy, manufacturing stage is the most significant contributor to the total energy consumption in all options.
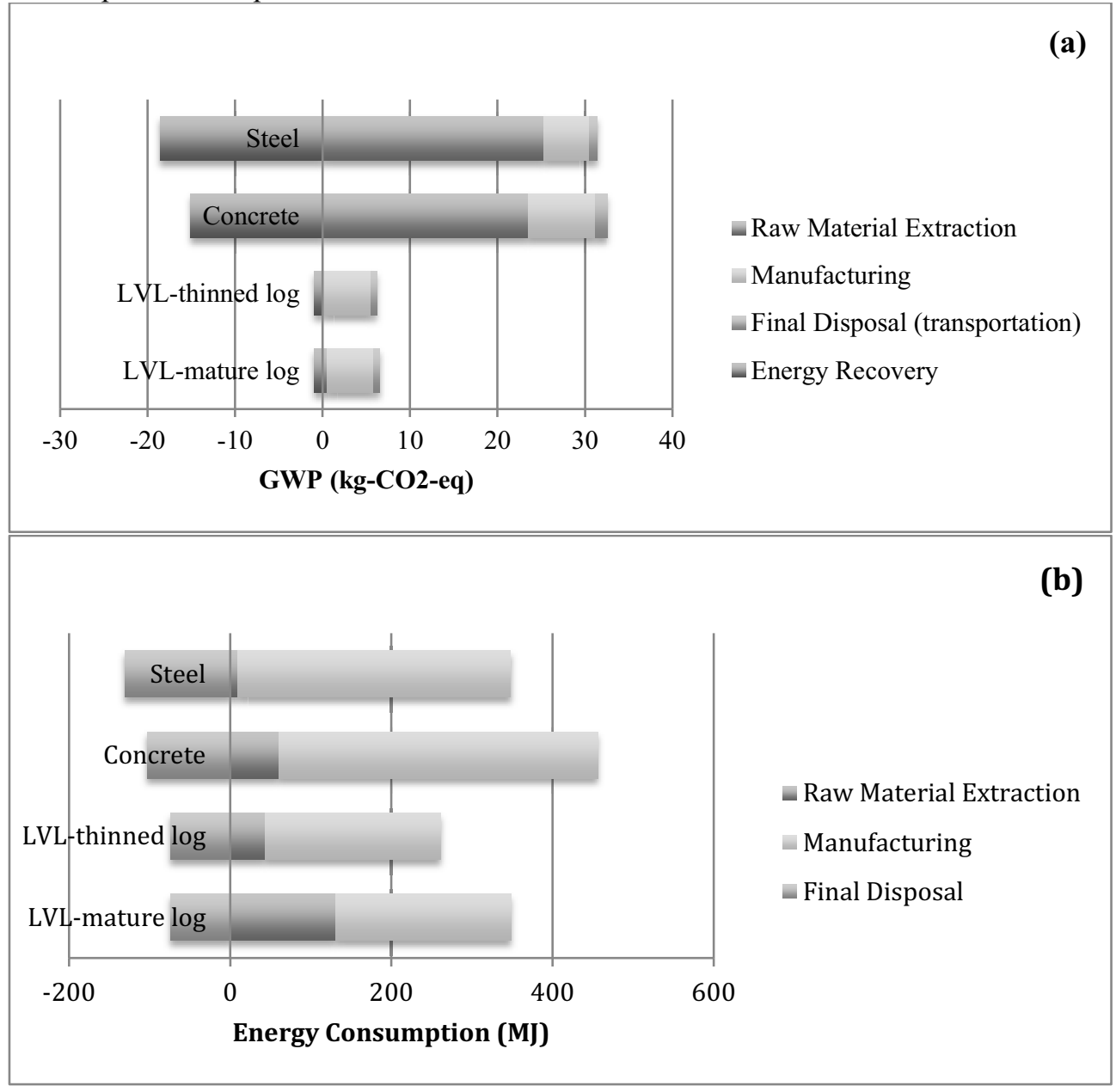

Fig. 2. (a) GHG emissions from each stage in four options (b) Energy consumptions from each stage in four options

The result indicated that the concrete had the largest environmental burden on GWP (17.43 $\mathrm{kg} \mathrm{CO}_{2}$-eq) mainly due to the significant transportation, fossil fuel consumption, as well as use of energy intensive materials during the manufacturing process. Steel structure beam has better environmental performance that concrete on GWP $(12.83 \mathrm{~kg} \mathrm{CO} 2$-eq $)$ than concrete beam. The GHG emissions released mainly from steel beam manufacturing and energy consumption. The energy required for casting concrete and steel beams were mostly sourced 
from fossil fuel attributed to electricity and natural gas consumption. However, the steel beam is recyclable at the end of its service life, which results in significant GHG emissions offset due to reduced energy requirements of recycled steel compared to virgin steel. Among all alternatives, LVL presented the best results on GWP mainly due to the use of significant amount of woody biomass fuel during the manufacture of LVL. According to IPCC (2007), $\mathrm{CO}_{2}$ emissions from burning biomass are not counted towards the GWP because it has recently been sequestered from the atmosphere [37]. Furthermore, the $\mathrm{CO}_{2}$ emissions from biomass burning were assumed to be sequestered by the next generation trees in the plantation. However, due to the significant energy requirements for wood drying, the embedded energy in LVL beam from thinned logs were about $186.78 \mathrm{MJ}$ which is only marginally less than steel $(216.86 \mathrm{MJ})$ but significantly less than concrete $(352.82 \mathrm{MJ})$. On the other hand, the embedded energy in the LVL beam manufactured from mature hardwood logs was calculated to be $274.2 \mathrm{MJ} / \mathrm{FU}$ which is higher than steel due to energy use during the plantation stage. Furthermore, in the case of LVL beam, the materials sourced from hardwood plantation thinning had relatively less environmental impact on GWP100 $\left(5.22 \mathrm{~kg}-\mathrm{CO}_{2}\right.$-eq $)$ than that from mature hardwood logs $(5.54 \mathrm{~kg}-\mathrm{CO} 2-\mathrm{eq})$, mainly due to avoided emissions during the plantation stage.

\subsection{Uncertainty and sensitivity analysis}

The uncertainties were caused by the variability and assumptions made in the LCA models. This section identified the most uncertain factors that may affect environmental performance. In this LCA, assumptions were made about transportation distance, energy resource consumption, as well as resin consumption, which introducing a level of uncertainty in the outcome of the LCA. Sensitivity analysis was conducted to identify the consequence by changing these uncertainties.

\subsubsection{Transportation distance}

Transportation distance during whole life cycle were estimated and obtained by an Internet highway directions interface [38]. However, the estimated route kilometres may not yield a real representation of actual transportation distance. A coefficient of variation $(\mathrm{CoV})$ of $20 \%$ is usually assumed for the estimation of transportation distance [39]. The sensitivity analysis indicated that the changes in transportation distances had more effect on GWP than embedded energy in all scenarios. LVL beam options were slightly more sensitive to the changes in transportation distances, which caused a variation of $\pm 16 \%$ in GWP impact indicator. Meanwhile the steel beam was the least sensitive, with GWP changing by less than $5 \%$. However, in absolute values, concrete continued to exhibit the highest impacts. This is due to the heavy weight of concrete beam leading to higher transportation emissions due to higher consumption of diesel fuel

\subsubsection{Energy consumption}

The energy consumption in manufacturing and service sector fell approximately $20 \%$ during the last decade due to the improvement in technology and economy structure [40]. Therefore, in this sensitivity analysis, two cases were modelled for comparison, including (1) energy consumption saving of $20 \%$, (2) increased energy consumption by $20 \%$. Changes in energy consumption had proportional effect on embedded energy of all options. Nevertheless, the changes in energy consumption have slightly higher effect on the GWP of concrete and steel beams, which are attributed to the high fossil fuel energy use during the manufacturing 
process. A change of $\pm 20 \%$ in energy consumption had $\pm 9 \%$ and $8 \%$ changes in GWP for the concrete and steel beam, respectively. On the other hand, both scenarios of LVL beams showed little sensitivity to changes in energy consumption $(< \pm 4 \%)$ for GWP. This can be attributed to the high proportion of biomass energy usage in the manufacturing process of the LVL beams.

\section{Conclusions and recommendations}

This study compared four alternatives options of structure beam in building construction sector by using life cycle approach. Engineered LVL beams made from both hardwood forestry mid-thinning and final harvest were compared to the more mature options of steel and concrete beam. Result of this study indicated that the LVL beam from mid-rotation thinning had much better performance on GWP. Low energy intensity and utilization of low value material in the manufacturing of the LVL beams were the most significant contributors. Additionally, using biomass fuel to substitute fossil fuel as energy source during manufacturing process led to significant reduction in GHG emissions. Concrete beam was the least favourite option due to high GWP. The largest impacts of concrete beam were mainly attributed to using energy intensive materials and its heavy weight, which required more energy during manufacturing and transportation. Steel beam performed slightly better than concrete beam mainly due to its lighter weight, which led to reduction in the energy and material consumption, as well as transportation. The steel recycling contributed to significant GHG emission offset. Two scenarios were considered for the LVL beams. However, the LVL beam sourced from thinned hardwood logs was a better performer from life cycle assessment perspective as it had lower environmental impacts mainly attributed to the avoided emissions during plantation stage. Additionally, due to the significant energy requirements for wood drying, the embedded energy in thinned wood LVL beam option was only marginally less than steel but significantly less than concrete. However, LVL from mature hardwood logs presented much higher embedded energy than the LVL beam from thinned log and steel beam options.

Therefore, in order to reduce the life cycle environmental impact, the manufacture of the three types of structure beams should strive to reduce energy and raw material inputs through conservation and innovation. For instance, the raw materials should be sourced from locations close to point of manufacturing facilities, which could help to reduce the emission generation and cost due to long distance transportation. Additionally, using bio-energy products to replace fossil fuel or electricity as the main energy source could significantly reduce environmental impacts.

\section{References}

1. B. Basaglia, K. Lewis, R. Shrestha, K. Crews, in International Conference on Performance-based and Life-cycle Structural Engineering, 1433-1442 (2015)

2. L. F. Cabeza, L. Rincón, V. Vilariño, G. Pérez, A. Castell, Renew. Sust. Energ. Rev. 29, 394-416 (2014)

3. I. Z. Bribián, A. V. Capilla, A. A. Usón, Build. Environ. 46, 1133-1140 (2011)

4. L. Wang, A. Toppinen, H. Juslin, J. Clean. Prod. 65, pp. 350-361 (2014)

5. C. Knowles, C. Theodoropoulos, C. Griffin, J. Allen, Can. J. Forest Res. 41, 390400 (2011)

6. L. Gustavsson, K. Pingoud, R. Sathre, Mitig. Adapt. Strat. G1. 11, 667-691 (2006)

7. R. Sathre, L. Gustavsson, Appl. Energ. 86, 251-257 (2009) 
8. C. J. Bradshaw, J Plant Ecol-UK 5, 109-120 (2012)

9. R. McGavin, M. Davies, J. Macgregor-Skinner, H. Bailleres, M. Armstrong, W. Atyeo, Forestry and Wood Products Australia, Melbourne, Australia (2006)

10. M. C. Barbu, R. Reh, M. Irle, Research Developments in Wood Engineering and Technology. IGI Global, 1-45 (2013)

11. F. Lam, Prog. Struct. Eng. Mat. 3, 238-245 (2001)

12. S. L. LeVan-Green, J. M. Livingston, J. Forest. 99, 25 (2001)

13. S. González-García, S. Berg, G. Feijoo, M. T. Moreira, Int. J. Life Cycle Ass. 14, 340-353 (2009)

14. B. Nebel, B. Zimmer, G. Wegener, Int. J. Life Cycle Ass. 11, 172-182 (2006)

15. J. Perez-Garcia, B. Lippke, D. Briggs, J. B. Wilson, J. Bowyer, J. Meil, Wood Fiber Sci. 37, 3-17 (2007)

16. A. B. Robertson, F. C. Lam, R. J. Cole, Buildings 2, 245-270 (2012).

17. International Standards Organisation (ISO), Environmental management-Life Cycle Assessment-Principles and Framework (ISO 14040, ed. Switzerland: second ed., 2006)

18. GreenDelta. (2014). OpenLCA. Available: http://www.openLCA.org

19. L. Aye, T. Ngo, R. Crawford, R. Gammampila, P. Mendis, Energ. Buildings 47, 159-168 (2012)

20. H. R. Lu, A. El Hanandeh, Sus. Proc. Consum. 5, 36-50 (2016)

21. Australian Standard AS 1720.1 (2010) Timber structures - Design methods (2010)

22. B. May, J. R. England, R. J. Raison, K. I. Paul, Forest Ecol. Manag. 264, 37-50 (2012)

23. E. Oneil, Cradle to Gate Life Cycle Assessment of Laminated Veneer Lumber Production from the Pacific Northwest (2013)

24. I. D. Underhill, B. P. Gilbert, H. Bailleres, R. L. McGavin, D. Patterson, Mater. Joints Timber Struct. 577-588 (2014)

25. R. D. Bergman, S. A. Bowe, Life-cycle inventory of manufacturing prefinished engineered wood flooring in the eastern United States, (University of Washington, Seattle, WA 2011)

26. D. E. Kline, Wood Fiber Sci. 37, 74-84 (2007)

27. S. Tucker, M. Syme, G. Foliente, NZ Timber Des J, 17, 3-9 (2009)

28. The New Australian Standard for Concrete Structures - AS3600 (2009)

29. National Renewable Energy Laboratory 2012 (U.S. Life Cycle Inventory Database, 2012)

30. AusLCI, The Australian National Life Cycle Inventory Database initiative (2011)

31. H. Bergsdal, R. A. Bohne, H. Brattebø, J. Ind. Ecol. 11, 27-39 (2007)

32. A. H. Buchanan, S. John, S. Love, World 15, 19 (2012)

33. Australian Standard for Steel Structures - AS4100 (1998)

34. GaBi Life Cycle Inventory Data Documentation (2016)

35. C. A. Bolin, S. T. Smith, J. Clean. Prod. 19, 630-639 (2011)

36. M. Yellishetty, G. M. Mudd, P. G. Ranjith, A. Tharumarajah, Environ. Sci. Policy $14,650-663$ (2011)

37. Intergovernmental Panel on Climate Change (IPCC), Climate Change 2007: The Physical Science Basis, Contribution of Working Group I to the Fourth Assessment Report of the Intergovernmental Panel on Climate Change (2007) Available: https://www.ipcc.ch/publications_and_data/publications_ipcc_fourth_assessment_ report_wg1_report_the_physical_science_basis.htm

38. Google Maps Directions (2016)

39. G. W. Sonnemann, M. Schuhmacher, F. Castells, J. Clean. Prod. 11, 279-292 (2003)

40. S. Voigt, E. De Cian, M. Schymura, E. Verdolini, Energ. Econ. 41, 47-62 (2014) 